\title{
COMPARATIVE PHYTOCHEMICAL ANALYSIS OF PHLOGACANTHUS THYRSIFLORUS NEES: IMPLICATIONS ON ATTENUATION OF PRO-OXIDANTS AND PATHOGEN VIRULENCE IN CAENORHABDITIS ELEGANS MODEL SYSTEM
}

\author{
KITLANGKI SUCHIANG*, NITASHA HIMANSHU KAYDE
}

Department of Biochemistry and Molecular Biology, Pondicherry University, Puducherry, India. Email: kitlangkisuchiang@gmail.com Received: 27 January 2016, Revised and Accepted: 01 March 2017

ABSTRACT

Objectives: Phlogacanthus thyrsiflorus Nees of Acanthaceae family is endogenous to sub-tropical Himalayas. It has been reported to be used traditionally in Jaintia tribe of Meghalaya, India, for the treatment of many ailments. The aim was to detect the active compounds present in the leaves and evaluation of its in vitro free radicals scavenging potential. Leaves protective effects in vivo will be investigated using Caenorhabditis elegans model system utilizing wild type and mutant strains and the phenomena of host-pathogen interactions.

Methods: Gas chromatography-mass spectrometry was used for detection of different compounds present. The versatility of leaf extracts to scavenge different free radicals generated in vitro was assessed with different in vitro methods. Survival analysis of wild type and mutant strains $C$. elegans under enhanced pro-oxidants exposure was investigated in vivo. The fast killing assay was also performed to study the extracts modulatory activities on host C. elegans survival under pathogen Pseudomonas aeruginosa infection.

Results: About 40 compounds were detected in methanolic fraction of the extract with variable percentages. Both aqueous and methanol extract possessed remarkable, versatile free radical scavenging activity irrespective of the types of free radical generated. The in vivo experiments are in compliance with observable increased survival ability percentage of C. elegans under intense exogenous oxidative stress and pathogen infection.

Conclusion: Our findings enlightened the different bioactive compounds present with versatility of $P$. thyrsiflorus in tackling different free radicals generated both in vitro and in vivo that highly support for its candidature as a good antioxidant source. Our findings may justify the historical relevance of this plant in herbal remedies that could form the basis for inquiry of new active principles.

Keywords: Free radicals, Oxidative stress, Caenorhabditis elegans, Phlogacanthus thyrsiflorus, Phytochemicals.

(c) 2017 The Authors. Published by Innovare Academic Sciences Pvt Ltd. This is an open access article under the CC BY license (http://creativecommons. org/licenses/by/4. 0/) DOI: http://dx.doi.org/10.22159/ajpcr.2017.v10i5.17319

\section{INTRODUCTION}

Cells are inherently equipped with an impressive repertoire of integrated antioxidant and immune systems for a sustained protection of an organism. However, with an unavoidable consequence of aerobic metabolism, a stepwise unwanted reduction of molecular oxygen $\left(\mathrm{O}_{2}\right)$ under exposure or electron-transfer reactions leads to production of the highly reactive $\mathrm{O}_{2}$ species (ROS) and subsequently reactive nitrogen species $[1,2]$. When the level of ROS exceeds the antioxidative defense mechanisms, a cell is said to be in a state of "oxidative stress." Under this state, an overwhelmed ROS reacts and propagates with atoms of diverse biomolecules to modulate their functions. At the molecular levels, deregulations with an unwanted inhibition and activation of proteins, mutagenesis of DNA and gene transcription disrupts cell homeostasis to enhanced cell death and/or proliferation. Oxidative stress has been associated with the cause and etiologies of over hundreds of human diseases such as cancer, cardiovascular disease, aging, and neurodegenerative diseases [3,4].

Compounds which can maintain the level of ROS and modulate integrity of the immune system are important players in the amelioration and prevention of various diseases [5]. Antioxidants are diverse compounds pivotal in maintaining different cell types in a reduced environment. Thus, antioxidant ultimately helps in preserving the integrity and adequate function of membrane lipids, cellular proteins, and nucleic acids in signal transductions and gene expressions [6]. It is noteworthy that the traditional system of medicine has been practiced since historical times for curing ailments. Compounds isolated and derived from medicinal plants and other natural sources remain an important source of new drugs, new chemical entities and new drug leads [7-9].

Phlogacanthus thyrsiflorus Nees of Acanthaceae family is endogenous to sub-tropical Himalayas, upper Gangetic planes, Bihar, North Bengal, and North Eastern regions of India in the continent of Asia. The plant is an evergreen shrub up to $2.4 \mathrm{~m}$ high, branchlets quadrangular with leaves up to 13-35 cm long. P. thyrsiflorus, has been reported to be used traditionally for the treatment of many ailments [10,11]. Jaintia tribe of Meghalaya uses this plant for the historically significant antihyperglycemic, hypolipidemic, hepatoprotective activity they believed it possessed [12-14]. Considering its traditional medicinal values, this study is an attempt to evaluate on the different bioactive principles present, its antioxidative potentials both in vitro and in vivo using the genetically tractable model Caenorhabditis elegans which additionally can provide us with a useful tool to study plant potential on modulation of host immune system and the mechanism of hostpathogen interactions.

\section{METHODS}

Reagents and chemicals

All chemicals and reagents used were of analytical grade. They were obtained from the following companies: Sigma Chemical Company, St. Louis, USA; Thermo Fisher Scientific Pvt. Ltd. Mumbai, India; Santa Cruz Biotech; Qualigens and Himedia Laboratories, India. Miscellaneous were purchased locally. 


\section{Nematode strains}

The C. elegans strains used includes the wild type 'Bristol N2', which was kindly supplied by National Centre for Biological Sciences (NCBS), Bengaluru, India. Mutant strains which include GA480 [SOD-2 (gk257) I, SOD-3 (tm760) X.] and TJ1052 [age-1(hx546) II] strains were obtained from Caenorhabditis Genetics Center (CGC), University of Minnesota, St. Paul, MN, USA.

\section{Plant material}

Healthy disease free leaves of $P$. thyrsiflorus were collected from Dawki, West Jaintia Hills District, Meghalaya, India, and the submitted herbarium was identified by Dr. N. Parthasarathy, Professor, Department of Ecology and Environmental Sciences, Pondicherry University, India (Voucher no KSU101\#16). The collected sample was thoroughly washed and shade dried for 20-25 days, followed by pulverized with an electrical blender to obtain a powder form of the dried leaves. The powered samples were stored in an air tight container at room temperature without any exposure to sunlight for further use.

\section{Preparation of plant extracts}

Plant material was extracted using water (aqueous) and methanol solvents $(1: 10 \mathrm{w} / \mathrm{v})$. For aqueous extract, powdered leaves were extracted by macerated in water for $24 \mathrm{hrs}$ in a shaker. Then, the solution was first filtered through muslin cloth and Whatman filter paper No. 1, the filtrate thus obtained was concentrated and dried at $40^{\circ} \mathrm{C}$ using rotavapor. For methanol extract (ME), the dried leaf powdered was placed in the thimble of Soxhlet apparatus using $500 \mathrm{ml}$ of methanol as a solvent. The extraction was continued until the clear solvent was seen in the thimble. Finally, the solvent was concentrated in vacuum under reduced pressure using a rotary flask evaporator, allowed to evaporate until the dry powdered was obtained. All the collected, dried powdered samples were stored at $4^{\circ} \mathrm{C}$ for further use, and the percentage yield of the extract was calculated using the following formula

$$
\text { Percentage yield }=\frac{\text { Final weight of the dried extract }}{\text { Initial weight of the powder }} \times 100
$$

\section{Qualitative and quantitative phytochemical analysis}

Preliminary qualitative phytochemical analysis of extracts was performed as per the standard protocol [15]. Quantitatively, the total phenolic content of leaves was determined by Folin-Ciocalteu method [16]. The total alkaloid and flavonoid contents were determined according to methods described previously $[17,18]$. The mean of four readings repeated thrice was used and the total phenolic content was expressed in mg of gallic acid equivalents (GAE)/100 g dry weight of extract and flavonoids mg of quercetin equivalents $(\mathrm{QE}) / \mathrm{g}$ compound.

\section{Gas chromatography-mass spectrometry (GC-MS) analysis of the} extract

GC-MS analysis was performed using JEOL GCMATE II GC-MS spectrometer. This instrument was set to an initial temperature of $110^{\circ} \mathrm{C}$, and maintained at this temperature for 2 minutes. At the end of this period, the oven temperature was risen to $280^{\circ} \mathrm{C}$, at the rate of $5^{\circ} \mathrm{C} /$ minute, and maintained for 9 minutes. The injection port temperature was ensured as $250^{\circ} \mathrm{C}$ and helium flow rate as $1 \mathrm{ml} /$ minute. The ionization voltage was $70 \mathrm{eV}$. The samples were injected in split mode as 10:1. Mass spectral scan range was set at 45-450 (m/z). Using computer searches on a NIST Ver. 2.1 MS data library, comparing of the spectrum obtained through GC-MS compounds present in the plants sample were identified.

\section{In vitro antioxidant assay}

2, 2-diphenyl-1-picrylhydrazyl (DPPH) radical scavenging was determined by following standard protocol [19]. Hydrogen peroxide scavenging activity of plant extract was assessed by method as described [20]. Nitric oxide was generated from sodium nitroprusside and measured by Gries's reaction [21]. The chelating of ferrous ions by extracts was estimated by the method of Dinis [22], wherein the $\mathrm{Fe}^{2+-}$ chelating ability was monitored by the absorbance of the ferrous iron-ferrozine complex at $562 \mathrm{~nm}$. The total antioxidant capacity of the extracts was evaluated by phosphomolybdenum method [23]. Different concentrations of $\mathrm{AE}$ and $\mathrm{ME}$ were used and compared with ascorbic acid as positive control in all the assays.

\section{In vitro DNA damage protection assay}

Plasmid DNA nicking assay was performed using pUC 18 plasmid DNA as per the method described previously [24]. Briefly, $10 \mu \mathrm{l}$ of AE and ME (final concentration of $0.25 \mu \mathrm{g} / \mu \mathrm{l}$ and $0.5 \mu \mathrm{g} / \mu \mathrm{l}$ ) kept separately in Eppendorf tubes was mixed with plasmid DNA and incubated at room temperature followed by the addition of $10 \mu \mathrm{l}$ of Fenton's reagent ( $30 \mathrm{~mm} \mathrm{H} \mathrm{O}_{2}, 50 \mu \mathrm{M}$ ascorbic acid and $80 \mu \mathrm{M} \mathrm{FeCl}_{3}$ ). The final volume of the mixture was made up to $20 \mu \mathrm{l}$ and incubated for additional 30 minutes at $37^{\circ} \mathrm{C}$. Finally, $20 \mu \mathrm{l}$ of the sample was loaded in each well of $1.5 \%$ agarose gel, electrophoresed and the bands were visualized and photograph using Biorad gel documentation system.

\section{In vivo screening on C. elegans}

\section{Synchronization and culture conditions of C. elegans}

Worms GA480 [SOD-2 (gk257) I, SOD-3 (tm760) X.] and TJ1052 [age-1 (hx546) II] strains and wild type $\mathrm{N} 2$ were grown at $20^{\circ} \mathrm{C}$ on NGM medium spread lawn, fed with Escherichia coli OP50 strain (henceforth termed OP50) as food and maintained at $20^{\circ} \mathrm{C}$. Synchronized culture of gravid worms was obtained by lysis in an alkaline hypochlorite solution. The eggs were allowed to hatch in NGM plates at $20^{\circ} \mathrm{C}$ and young L1 were grown on NGM plates seeded with OP50.

\section{Oxidative stress resistance assay}

Pilot experiments were performed to ascertain the maximum time and dose used before the experiment [25]. The assay was performed in 96 well microtiter plates with $150 \mu \mathrm{l}$ of media/well in triplicates per condition (P10 worms/well) and the same experiment was repeated thrice at different times independently. Briefly, L3-L4 worms were transferred and allowed to grow for $30 \mathrm{hrs}$ in liquid S-medium with OP50 containing dissolved AE and ME at $1 \mathrm{mg} / \mathrm{ml}$ concentration. Control wells consist of worms that were incubated without the extract. After $30 \mathrm{hrs}$, worms were transferred to a freshly prepared liquid S-medium (supplemented with $200 \mu \mathrm{M}$ 5-Fluoro-2'deoxyuridine; FuDR). $10 \mathrm{~mm}$ tert-butyl hydroperoxide was added to the medium to induce oxidative stress at zero time and the survival rate of the worms was evaluated every $4 \mathrm{hrs}$ in a time-dependent manner. A worm was scored as dead when it did not respond to light mechanical stimulus.

\section{Fast killing assay}

Pilot experiments were performed to ascertain the different time and doses used in the experiment. Fast killing assay plates were prepared using peptone, glucose, and sorbitol agar containing $1 \%$ bacto-peptone, $1 \%$ glucose, $1 \% \mathrm{NaCl}, 150 \mathrm{~mm}$ sorbitol, and $1.7 \%$ bacto-agar [26]. To the plates, $50 \mu \mathrm{l}$ of the overnight grown culture of virulence strain PA14, Pseudomonas aeruginosa (PA) was added to the plates and allowed to grow for $24 \mathrm{hrs}$ at $37^{\circ} \mathrm{C}$, followed by transferring to $23^{\circ} \mathrm{C}$ for $24 \mathrm{hrs}$. Later, the solid plates were seeded with a synchronized population of L3-L4 worms previously incubated for $24 \mathrm{hrs}$ in liquid S-medium containing OP50 with dissolved AE and ME (final concentration of $0.5 \mathrm{mg} / \mathrm{ml}$ and $1 \mathrm{mg} / \mathrm{ml}$ ). Control plates consist of worms that were incubated without the extract. All the assays were performed in triplicate containing 20 worms/plate and the same experiment was repeated thrice independently. Finally, the plates were scored for dead worms every $8 \mathrm{hrs}$. A worm was considered dead and removed if it failed to move after gentle touch with a platinum wire worm picker.

\section{Statistical analysis}

All values reported are mean $\pm S D$ of four to five replicates in each group except for survival analysis. Data obtained from different sets were analyzed using Student's t-test for paired data. The level of significance 
$(\mathrm{p}<0.05)$ was considered to be statistically significant and reported as percentage or absorbance. The Kaplan-Meier analysis method was used for processing and plotting survival data against time [27].

\section{RESULTS}

Recovery percent, quantitative analysis, and total antioxidant capacity

The extract of $P$. thyrsiflorus was prepared as described and the percent yield was found to be $12.6 \%$ for AE and $15 \%$ for ME. Quantitative analysis results showed that total phenolic content present in $\mathrm{AE}$ and $\mathrm{ME}$ at 18 and $21 \mathrm{mg} \mathrm{GAE} / \mathrm{g}$ of phenolic compounds. The total flavonoid content of $\mathrm{AE}$ and $\mathrm{ME}$ was found to be 9 and $31.8 \mathrm{mg} \mathrm{QE} / \mathrm{g}$ of flavonoids. Finally, the total alkaloid content present for $\mathrm{AE}$ is approximately 5.5 and ME at $16.5 \mathrm{mg} / \mathrm{g}$ of extract. Preliminary qualitative phytochemical analysis of extracts showed the presence of metabolites such as carbohydrates, proteins, flavonoids, phenols, steroids, terpenois, cardiac glycosides, tannins, quinones, and saponins (Fig. 1).

\section{GC-MS analysis}

To elucidate the chemical profile of the plant, we performed the GC-MS analysis of ME. Our result revealed the presence of 40 phytochemical constituent compounds that could contribute to the medicinal quality of the plant. The major bioactive principles with their retention time (RT), molecular formula, molecular weight, and peak area in percentage are presented in Fig. 2. The first compound identified with less RT (10.545) was phenol 2, 6-dimethoxy whereas 2-ethylacridine was the last compound which took longest RT (33.839 minutes). The GC-MS analysis of extract revealed the abundance of phytol with the highest percentage followed by hexadecanoic acid, methyl ester, stigmasterol, alloaromadendrene, squalene, and 1, 8-diamino-3, 6-dioxaoctane compounds. The detailed reports of some of the major compounds present are listed in Table 1.

\section{In vitro antioxidant assays}

\section{DPPH and hydroxyl radical scavenging assay}

Percentage of DPPH scavenging activity of AE and ME increases with increased in extract concentration. In comparison with a $96.70 \%$ inhibition of ascorbic acid, $\mathrm{AE}$ and $\mathrm{ME}$ exhibited an inhibitory percentage of $42.95 \%$ and $72.13 \%$ at $300 \mu \mathrm{g} / \mathrm{ml}$, respectively (Fig. 3a). From Fig. $3 \mathrm{~b}$ it can be inferred that the $\mathrm{OH}$ - radical scavenging activity of $\mathrm{AE}$ and $\mathrm{ME}$ also increased with increases in extract concentration. AE with $68.9 \%$ inhibitory activity possessed a comparatively better $\mathrm{OH}$ - scavenging activity than ME with $61.2 \%$ at $500 \mu \mathrm{g} / \mathrm{ml}$.
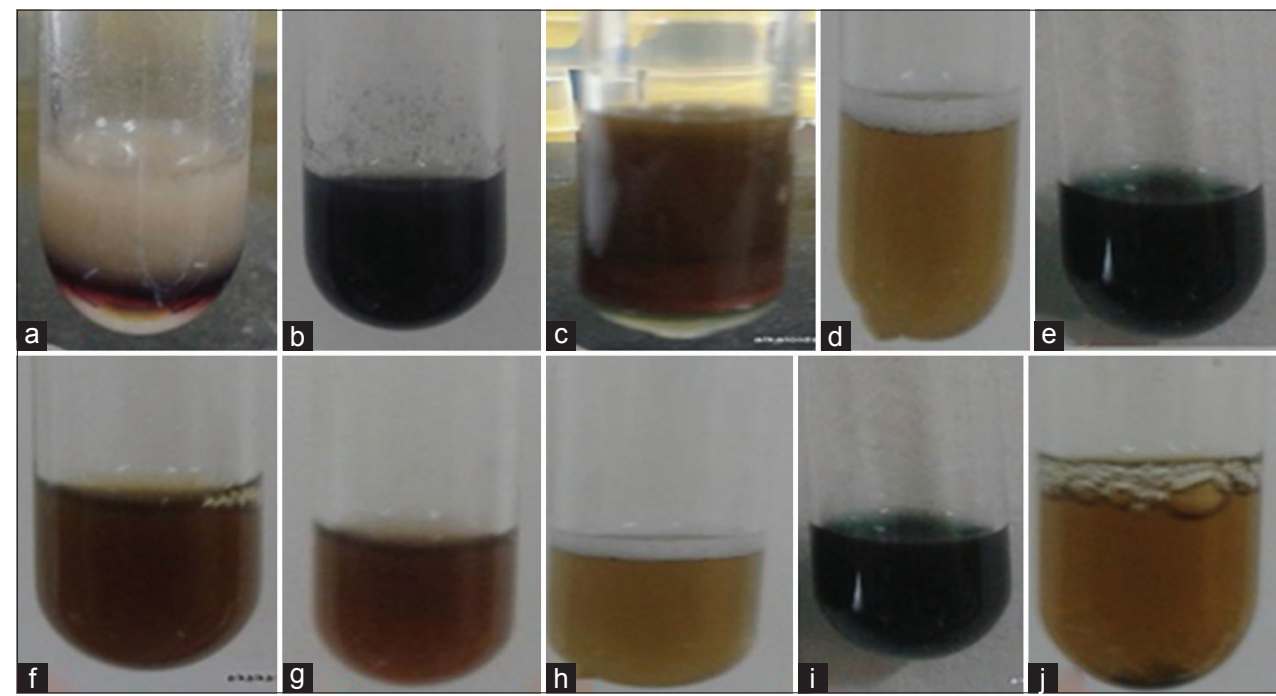

Fig. 1: Preliminary qualitative phytochemical analysis of aqueous extract showed the presence (a) carbohydrates (b) proteins (c) flavonoids (d) phenols, (e) steroids (f) terpenois (g) cardiac glycosides (h) tannins (i) quinones (j) Saponins

Table 1: Major compounds identified in the methanol extract of $P$. thyrsiflorus Nees by GC-MS

\begin{tabular}{|c|c|c|c|c|}
\hline RT & Compound name & Formula & Mol wt. & PA\% $\%$ \\
\hline 10.545 & Phenol, 2,6-dimethoxy- & $\mathrm{C}_{8} \mathrm{H}_{10} \mathrm{O}_{3}$ & 154.1 & 2.32 \\
\hline \multirow[t]{2}{*}{13.917} & Dispiro [2.2.2.2] deca-4,9-diene & $\mathrm{C}_{10}^{8} \mathrm{H}_{12}^{10}$ & 132 & 3.19 \\
\hline & $\mathrm{N}, \mathrm{N}$-dimethyltrimethylsilamine & $\mathrm{C}_{5}^{10} \mathrm{H}_{15}^{12} \mathrm{NSi}$ & 117 & 3.19 \\
\hline 14.393 & 1,8-diamino-3,6-dioxaoctane & $\mathrm{C}_{6}^{5} \mathrm{H}_{16}^{15} \mathrm{~N}_{2} \mathrm{O}_{2}$ & 148 & 2.24 \\
\hline 15.629 & Benzoic acid, 4-hydroxy-3,5-dimethoxy-, hydrazide & $\mathrm{C}_{9}^{6} \mathrm{H}_{12}^{16} \mathrm{~N}_{2}^{2} \mathrm{O}_{4}^{2}$ & 212 & 2.21 \\
\hline 15.930 & Orcinol & $\mathrm{C}_{7} \mathrm{H}_{8} \mathrm{H}_{2} \mathrm{O}^{2}$ & 124 & 1.84 \\
\hline 16.190 & 2,6,6-trimethyl-bicyclo[3.1.1]heptane, trans & $\mathrm{C}_{10}^{7} \mathrm{H}_{18}^{8}$ & 138 & 1.36 \\
\hline 18.805 & 9-Octadecenoic acid (Z)-, methyl ester & $\mathrm{C}_{19}^{17} \mathrm{H}_{36}^{34} \mathrm{O}_{2}^{2}$ & 296.4 & 1.69 \\
\hline 18.902 & Phytol & $\mathrm{C}_{20}^{19} \mathrm{H}_{40}^{36} \mathrm{O}^{2}$ & 296.5 & 8.55 \\
\hline 19.043 & Methyl stearate & $\mathrm{C}_{19} \mathrm{H}_{38} \mathrm{O}_{2}$ & 298.5 & 0.92 \\
\hline 21.026 & Cyclopropane, isothiocyanate- & $\mathrm{C}_{4} \mathrm{H}_{5} \mathrm{NS}^{2}$ & 99.1 & 0.67 \\
\hline 22.482 & 7H-Purin-6-amine, 7-methyl- & $\mathrm{C}_{6}^{4} \mathrm{H}_{7}^{5} \mathrm{~N}_{5}$ & 149.1 & 1.78 \\
\hline 24.525 & Squalene & $\mathrm{C}_{30}{ }^{6} \mathrm{H}_{50}{ }^{5}$ & 410.7 & 2.61 \\
\hline 25.127 & Alloaromadendrene & $\mathrm{C}_{15}^{30} \mathrm{H}_{24}^{50}$ & 204.3 & 3.02 \\
\hline 26.583 & Stigmasterol & $\mathrm{C}_{29}^{15} \mathrm{H}_{48}^{24} \mathrm{O}$ & 412.69 & 4.11 \\
\hline 33.989 & 2-Ethylacridine & $\mathrm{C}_{15}^{12} \mathrm{H}_{13}{ }^{13} \mathrm{~N}$ & 207.2 & 0.96 \\
\hline
\end{tabular}

RT: Retention time, Mol wt: Molecular weight, PA\%: Peak area percentage, P. thyrsiflorus: Phlogacanthus thyrsiflorus 


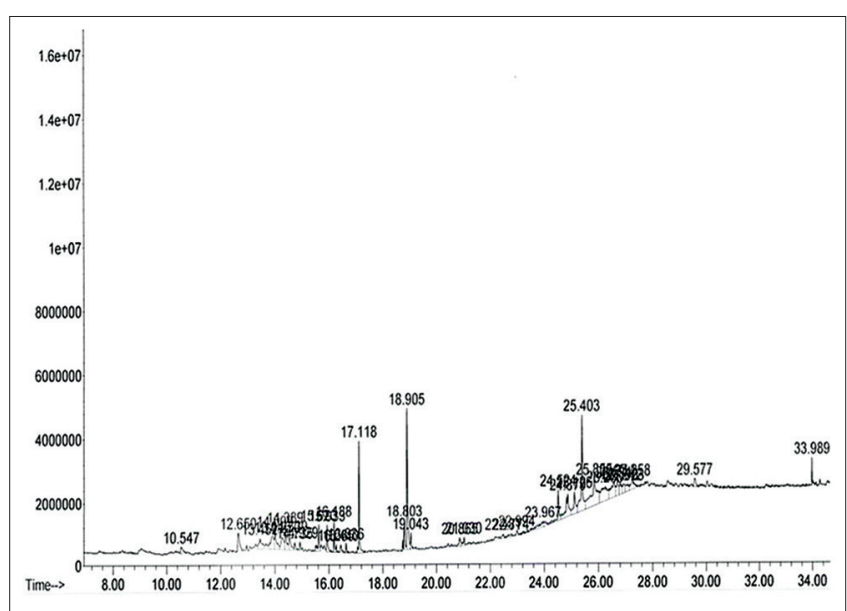

Fig. 2: Gas chromatography-mass spectrometry chromatogram of methanolic extract of Phlogacanthus thyrsiflorus

\section{$\mathrm{H}_{2} \mathrm{O}_{2}$ and nitric oxide radical scavenging activity}

The percentage of $\mathrm{H}_{2} \mathrm{O}_{2}$ scavenging activity of $\mathrm{AE}$ and $\mathrm{ME}$ was found to be $87.5 \%$ and $90.7 \%$, at par with that of ascorbic acid which exhibited a $91.3 \%$ inhibitory percentage at $200 \mu \mathrm{g} / \mathrm{ml}$ (Fig. 3c). Fig. 3d depicts the scavenging activity of extracts for nitric oxide radical. The percentage inhibition was in the order of ascorbic acid $>\mathrm{ME}>\mathrm{AE}$ with a corresponding inhibitory percentage of $65.6 \%, 60 \%$, and $41.5 \%$, respectively.

Total antioxidant capacity and ferrous $\left(\mathrm{Fe}^{2+}\right)$ ion chelating assay The total antioxidant capacity of the $P$. thyrsiflorus leaf extracts was determined by phosphomolybdate method and the increased in absorbance at $695 \mathrm{~nm}$ indicated higher total antioxidant capacity. Our results depicted uniform increased in absorbance from 100 to $500 \mu \mathrm{g} / \mathrm{ml}$ in all the three samples studied, with total antioxidant capacity in the order of ascorbic acid $>\mathrm{ME}>\mathrm{AE}$ (Fig. 3e). Fig. 3f represented the ferrous ions $\left(\mathrm{Fe}^{2+}\right)$ chelating activities of $P$. tyrsiflorus extracts which were found to be comparatively higher than ascorbic acid at $200 \mu \mathrm{g} / \mathrm{ml}$. This percentage chelation activity was in the order of $\mathrm{ME}>\mathrm{AE}>$ ascorbic acid corresponding with percentage of $64.3 \%, 62.7 \%$, and $58.5 \%$, respectively.

\section{In vitro DNA damage protective assay}

Hydroxyl $(\cdot \mathrm{OH})$ radicals generated by the Fenton's reaction are known to induced breaks in DNA strands. Fig. 4 of agarose gel migration image showed that when plasmid DNA was dissolved in Fenton's reagent, electrophoretically two visible bands were observed due to the formation of open circular DNA (OC-Form) in lane 2 besides the intact supercoil DNA (SC-Form) in lane1. Addition of extracts resulted in the partial or full recovery of super coiled DNA (Lane 3-6). In comparison with AE, ME loaded in lane 5 and 6 exhibited maximum recovery of SCForm irrespective of the concentrations used (Fig. 4).

\section{In vivo screening on C. elegans}

\section{Oxidative stress resistance assay}

The effect of tert-butyl hydroperoxide $(10 \mathrm{~mm})$ treatment on the survival time of untreated wild type control and mutated C. elegans strains was investigated until all the worms were dead (zero survival). Our results showed that TJ1052 mutants survive the longest with 44 hrs survival time, followed by $\mathrm{N} 2$ wild type with $32 \mathrm{hrs} \mathrm{(Fig.} 5 \mathrm{a}$ and c). Oxidative stress sensitive strain GA480 has the shortest survival time with zero survival corresponding at $24 \mathrm{hrs}$ (Fig. 5b). Taking into account the time of zero survival in individual strain as mentioned, treatment with $\mathrm{AE}$ and ME showed increased survival percentage in all the strains studied. Our data revealed that $\mathrm{N} 2$ worms previously treated with $\mathrm{AE}$ and ME exhibited a $90.47 \%$ and $88.37 \%$ survival percentage at $32 \mathrm{hrs}$ whereas, GA480 strain exhibited a $75.0 \%$ and $71.45 \%$ survival percentage at
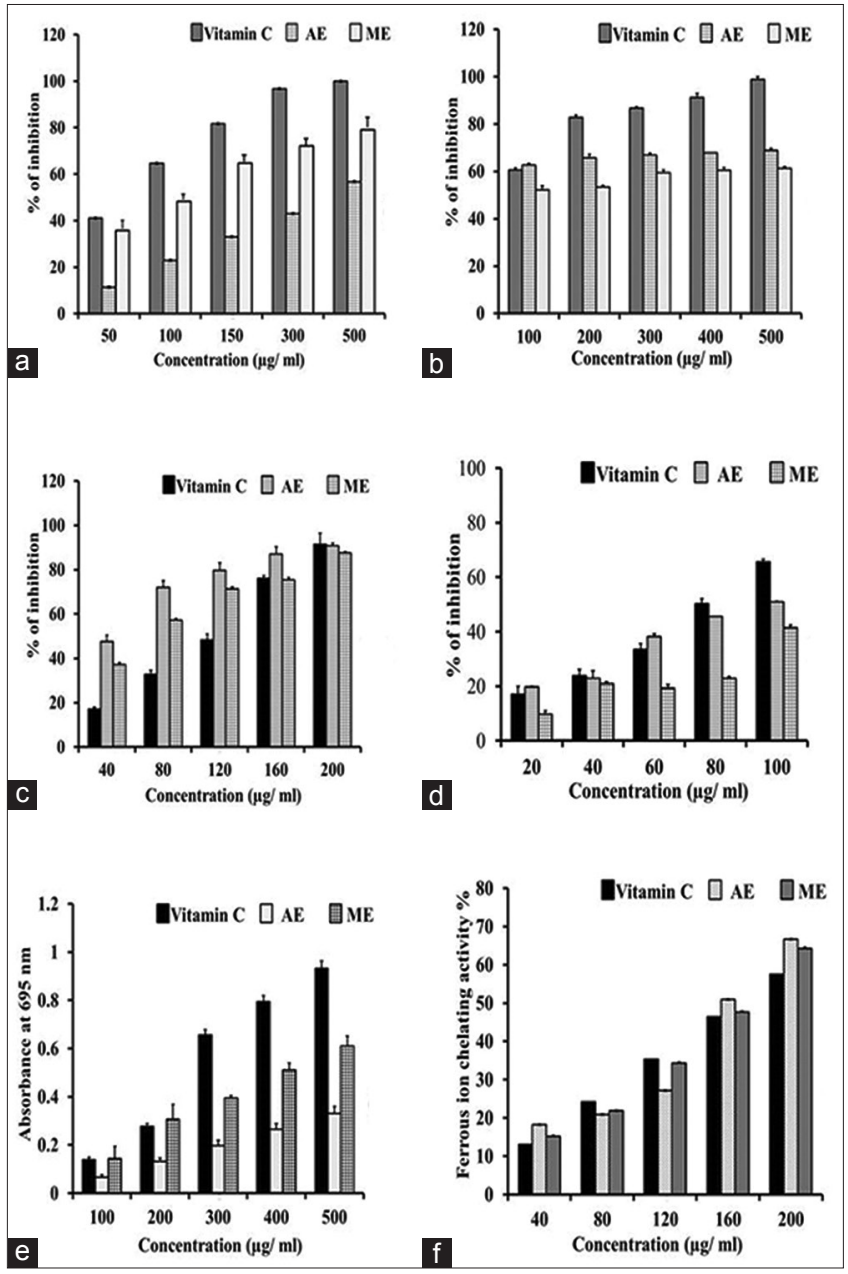

Fig. 3: In vitro antioxidant activities of AE and ME: (a) DPPH radical scavenging activity, (b) hydroxyl radical scavenging activity, (c) hydrogen peroxide scavenging activity, (d) nitric oxide radical scavenging activity, (e) total antioxidant activity, (f) ferrous ion $\left(\mathrm{Fe}^{2+}\right)$ chelating activity

24 hrs (Fig. 5a and b). Furthermore, TJ1052 treated with AE and ME showed a survival percentage of $65.7 \%$ and $62.85 \%$ at 44 hrs (Fig. 5c). In addition, preliminary assays were done before this study and no observable effect of the added plant extracts on worm survival, lifespan or brood size on OP50 (data not shown), indicating a lack of toxicity of the compounds present.

\section{Fast Killing assay}

C. elegans is commonly used as an infection model for pathogenesis studies in $P$. aeruginosa. The standard virulence assays rely on the slow and fast killing or paralysis of nematodes. The ability of plant extract to protect $C$. elegans from PA infection under fast killing assay was demonstrated in Fig. 6. After $72 \mathrm{hrs}$, the survival of the AE treated nematode was found to be $48 \%$ and $63 \%$, respectively, at $0.5 \mathrm{mg} / \mathrm{ml}$ and $74 \%$ at $1 \mathrm{mg} / \mathrm{ml}$ (Fig. 6a). Similarly, ME showed a similar protective ability with the worms survival percentage of $62 \%$ at $0.5 \mathrm{mg} / \mathrm{ml}$ and $74 \%$ at $1 \mathrm{mg} / \mathrm{ml}$ (Fig. 6b). In addition, both AE and ME exhibited no inhibition sign on PA growth and/or perturbation of C. elegans feeding rate. This directly indicated that the observable effect of extracts on the survival of host worms is by modulation of toxins generated and/or enhance its various defences against the pathogen (Fig. 7a, b and c).

\section{DISCUSSION}

Our in vitro experiments indicated that both $\mathrm{AE}$ and ME possessed remarkable, versatile, free radicals scavenging activities irrespective 


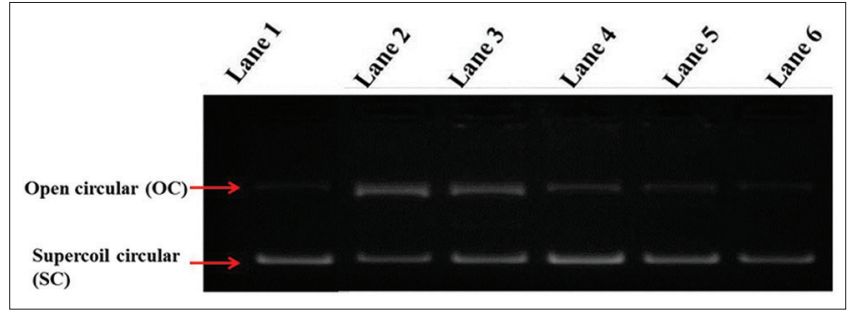

Fig. 4: DNA protective assay using pUC 18 plasmid. Representative lane includes: Lane 1: DNA (pUC18 plasmid alone)

Lane 2: DNA + Fenton reagent, Lane 3: DNA + Fenton reagent +

$0.25 \mu \mathrm{g} / \mu \mathrm{l} \mathrm{AE}$, Lane 4: DNA + Fenton reagent + $0.50 \mu \mathrm{g} / \mu \mathrm{l} \mathrm{AE}$

Lane 5: DNA + Fenton reagent + $0.25 \mu \mathrm{g} / \mu \mathrm{l} \mathrm{ME}$, and Lane 6: DNA + Fenton reagent $+0.50 \mu \mathrm{g} / \mu \mathrm{l} \mathrm{ME}$

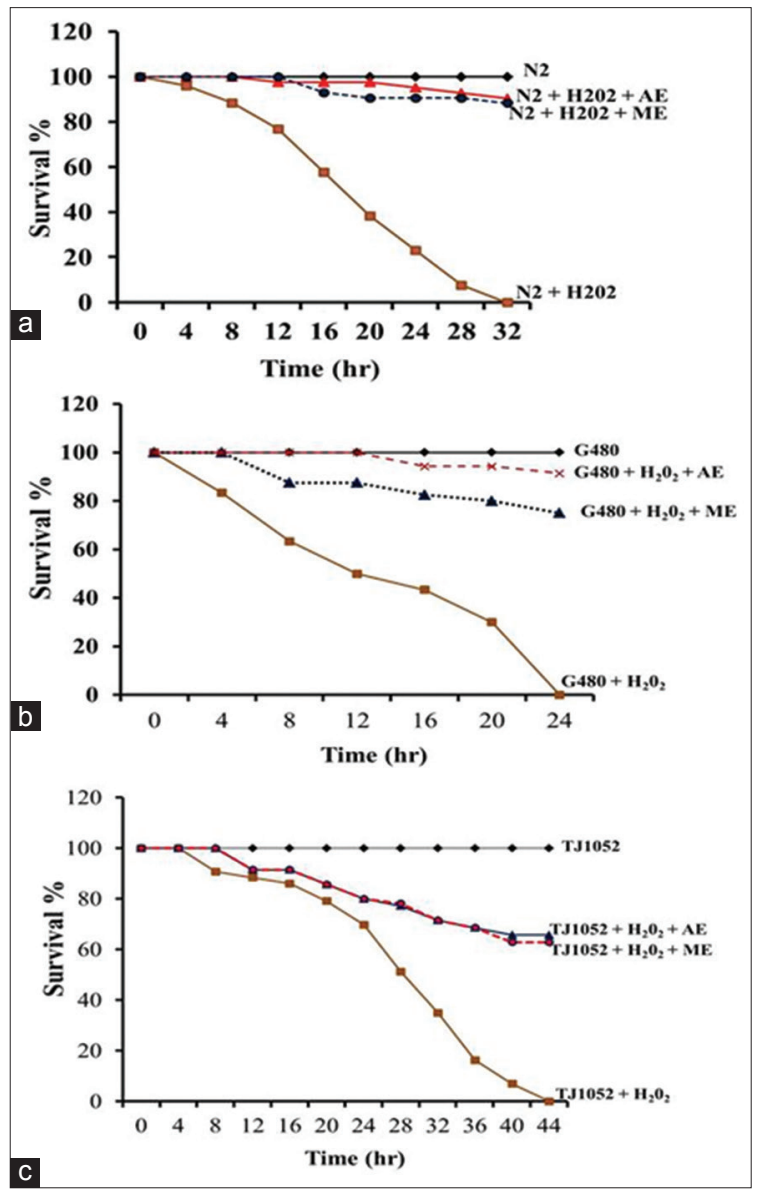

Fig. 5: In vivo effects of aqueous and methanol leaf extract against tert-butyl hyroperoxide induced oxidative stress on the survival of (a) N2 wild type (b) G480 and (c) TJ1052 mutant strains. Results are presented as percentage in comparison with respective control group

of free radical generated. This overall significantly higher inhibition percentage can be positively correlates with the total phenolic, flavonoid, and alkaloid content present and the abundance of active and lead compounds as depicted in GC-MS analysis. By its capability to reduce a stable free radical DPPH, extracts provide us with a first clue that there were compounds present to donate an electron or hydrogen to DPPH, can react with it and thereby bleach the DPPH absorption. The significant $\mathrm{OH} \cdot$ radical scavenging activity observed provides an additional and direct evidences that protection from the most common and single unpaired electron encountered in aerobic organism is possible thereby, its reactivity with all biological molecules

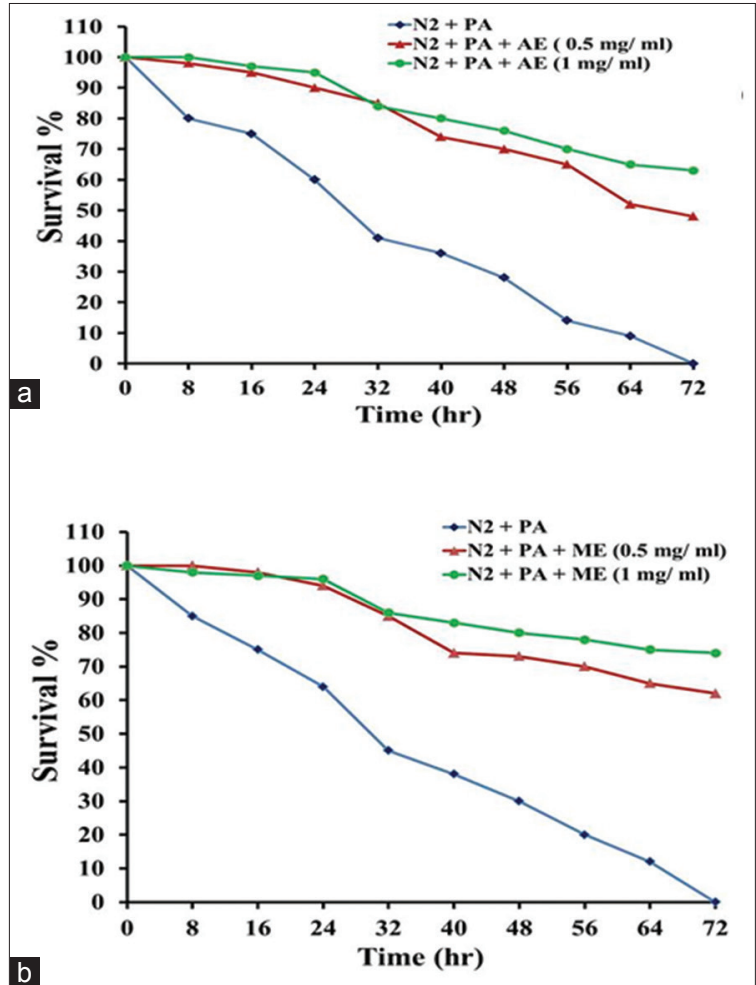

Fig. 6: Survival of N2 wild type Caenorhabditis elegans under Pseudomonas aeruginosa fast killing assay. (a) Represents worms treated previously with aqueous and (b) worms treated previously with methanol extract. Results are presented as percentage in comparison with respective control group
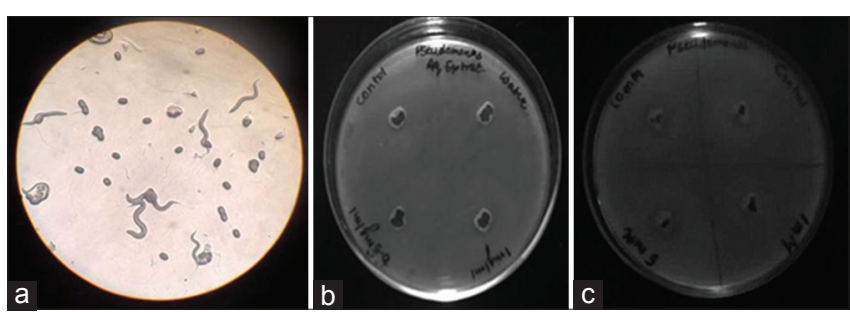

Fig. 7: (a) Population of Caenorhabditis elegans L-3 and L-4 worms with eggs. Disc diffusion method for Pseudomonas aeruginosa growth inhibition in the presence of (b) aqueous extract, and (c) methanol extract at 0.5 and $1 \mathrm{mg} / \mathrm{ml}$ concentration. No visible inhibition zones were observed

and subsequent declined in cellular damages such as lipid peroxidation, protein damage, and membrane destruction can be ameliorated $[5,6]$. In addition, although not so common, NO- radical toxicity increases greatly when it reacts with superoxide radical, forming the highly reactive peroxynitrite anion (ONOO-), an effective chain terminating agent in free radical mediated lipid oxidation with well-established role in carcinoma and inflammatory processes [28]. Thus, by scavenging NO radical, compounds present in extracts helps in breaking of the chain reactions with an ultimate reduced toxicity that could play a role in protecting the physicochemical properties of membrane bilayers from free-radical induced severe cellular dysfunction. Finally, by having a ferrous ions $\left(\mathrm{Fe}^{2+}\right)$ chelation activity, extracts renders an important effect via. Inhibiting metal-catalyzed oxidation reaction, halting directly at the main source of ROS production as applicable within animal and human systems [29].

At the nucleic acids level, oxidative modification of DNA has been suggested to contribute to aging and various diseases including 
cancer and chronic inflammation. Our results clearly showed that both AE and ME rescued pUC18 plasmid DNA against damage caused by hydroxyl radical. The DNA cleavage analysis provides evidence that compounds present in P. thyrsiflorus extracts can directly or indirectly have a role in mutual antagonism relevance with genotoxicity and mutagenicity. It is also interesting to note that recent studies suggest that phytol, the most abundant compound present in this plant can indeed reduce both production of free radicals besides scavenging activity, a link directly correlated to its unique structural feature of branched-chain unsaturated alcohol [30,31]. Similarly, phytosterols such as stigmasterol, squalene, and isothiocyanates detected are reported to be responsible, at least in part, for preventive effects on the development of diseases due to ROS against lipid peroxidation [32-34]. With this study limitations and the rich active principles present in a single plant observed, we suggests that the synergism like effect of different compounds present provide a combinational advantages of synergy in efficacy thereby, cumulative with pronounced versatility against different free radicals and nuclei acid protection were observed.

The role of oxidative stress in C. elegans lifespan has been investigated in several different ways. Correlations between life span and various aspects of oxidative metabolism have been examined together; with studies typically either examines age changes in wild type nematodes or differences between wild type nematodes and mutants with altered rates of aging. Our studies conceptualized on the idea that if ROS can accelerate and modulate survival and aging, then manipulating ROS levels should affect mortality and survival rate. Superoxide dismutase (SOD), the first line of antioxidant enzyme acts by converting superoxide to hydrogen peroxide, which can subsequently be converted to water by catalase or peroxiredoxin. In this study, we found that GA480 (mutants for SOD-2 and SOD-3) worms were indeed sensitive to induced oxidative stress by displaying the shortest survival time and/or zero survival within $24 \mathrm{hrs}$ after treatment. We speculated that although under normoxic conditions, additional SOD's, chemical and enzymatic antioxidants may be useful for normal organismal defenses against oxidative damage, but under conditions of extreme oxidative burst like the prevailing experimentally induced elevation, the compensation for the loss of crucial function due to mutation can be easily overwhelmed and this may contribute to the shortest survival as seen in the case of G480 in comparison to N2 and TJ1052 with normal and overexpress SODs.

Furthermore, our findings clearly showed that groups treated with extracts exhibited significantly higher survival percentage in all the strains of C. elegans studied. We suggest that during this period of rapid oxidative burst, different compounds present as mentioned earlier can individually and/or synergistically modulate the loads of free radicals generated by donating an electron for reducing and converting them into stable unreactive metabolites. These benefits are thus manifested manifold either directly in the form of less macromolecular oxidative damage, besides safeguarding the normal functioning of active integrated antioxidant systems from the overwhelming effects of oxidative stress. In totality, the abundance of different antioxidative compounds as seen in the extracts can give a kind of compensation required for the altered SOD of G480 besides an enhanced additional protection to N2 and TJ1052 strains with an intact system for their better survival.

It is also noteworthy to mention that there are numerous aging genes that have been found to cause at least a $20 \%$ increase in the lifespan of C. elegans. TJ1052, an age-1 mutants are one such example with long life, normal fertility, and stress tolerant. Recent findings have revealed that long-lived age- 1 mutants have increased SOD and catalase activity levels, which led to their resistance to oxidative stress in comparison to the wild type $[35,36]$. Other studies conducted by Honda et al. have shown that age- 1 mutation leads to oxidative stress resistance phenotype in C. elegans by regulating through the insulin signaling pathway [37]. With an unclear common mechanism till date, our present findings of TJ1052 worms exceptional resistant to oxidative and electrophilic stresses, with prolonged survival time will further contribute substantially to the notion that indeed age-1 mutation strain has some favorable alterations in molecular expression/signaling events corresponding to the beneficial oxidative metabolism which contributed significantly to its longer lifespan. Furthermore, our findings also lend support to the hypothesis that oxidative stresses comprise key contributors to the process of aging [38], and that longevity depends at least in part on the balance between the generation of such stresses and resistance to them $[39,40]$.

In fast killing assay, C. elegans death occurred within a period of hours and it was reported that the damage was caused due to the phenazines, low molecular-weight diffusible toxins excreted by PA [41,42]. Our results clearly demonstrated the ability of $P$. thyrsiflorus extracts in rescuing $C$. elegans from fatal PA infection. This allows us to speculate that besides enhancing the integrated antioxidative system of the host, compounds present in the plant can lead to the chemical modification of toxic phenazines to a lesser toxic intermediates thereby providing, with an ultimate protective effects to the host. Recently, forward genetic approach to identify components of a presumptive $C$. elegans innate immune response pathway upstream of induced defense responses has led to the discovery that a C. elegans homolog of the mammalian p38 mitogen-activated protein kinase is an important component that is upregulated in C. elegans defense response to bacterial pathogens [43-45]. Natural extracts or compounds present in plants are also reported to have immunomodulatory activities [46,47]. Alternatively, the presence of compounds in extracts capable of modulating the immune system of the host to fight against the penetration of invading pathogen cannot be ruled out and this speculation needs further evaluation.

\section{CONCLUSION}

It is worth mentioning that the data obtained from this study enlightened the different versatility of $P$. thyrsiflorus in tackling different free radicals generated both in vitro and in vivo in C. elegans that highly support for its candidature as a good antioxidant source. This work also showed the presence of many pharmacologically bioactive principles, which needs to be elucidated for their potential modulation on different molecules and signaling involved. This may help to develop a herbal medicinal product or an effective therapeutic agent involving immune modulation and strategy based biomedical usefulness in controlling different oxidative stress and age-related pathophysiological conditions.

\section{ACKNOWLEDGMENTS}

The authors acknowledge the Department of Biochemistry and Molecular Biology, Pondicherry University for financial support. The authors also thank the UGC and DST, in the form of DST-FIST Government of India, New Delhi. The authors deeply thank National Centre for Biological Sciences (NCBS), Bengaluru, India and Caenorhabditis Genetics Centre (CGC), University of Minnesota, St. Paul, MN, USA for the kind supplier of C. elegans.

\section{REFERENCES}

1. Dröge W. Free radicals in the physiological control of cell function. Physiol Rev 2002;82(1):47-95.

2. Young IS, Woodside JV. Antioxidants in health and disease. J Clin Pathol 2001;54(3):176-86.

3. Harman D. Aging: A theory based on free radical and radiation chemistry. J Gerontol 1956;11(3):298-300.

4. Nathan C, Cunningham-Bussel A. Beyond oxidative stress: An immunologist's guide to reactive oxygen species. Nat Rev Immunol 2013;13(5):349-61.

5. Willcox JK, Ash SL, Catignani GL. Antioxidants and prevention of chronic disease. Crit Rev Food Sci Nutr 2004;44(4):275-95.

6. Knight JA. Review: Free radicals, antioxidants, and the immune system. Ann Clin Lab Sci 2000;30(2):145-58.

7. Butler MS. The role of natural product chemistry in drug discovery. J Nat Prod 2004;67(12):2141-53.

8. Lombardino JG, Lowe JA $3^{\text {rd }}$. The role of the medicinal chemist in drug discovery - Then and now. Nat Rev Drug Discov 2004;3(10):853-62. 
9. Kathiravan G, Sureban SM, Sree HN, Bhuvaneshwari V, Kramony E. Isolation of anticancer drug TAXOL from Pestalotiopsis breviseta with apoptosis and B-Cell lymphoma protein docking studies. J Basic Clin Pharm 2012;4(1):14-9.

10. Singh SA, Singh NR. Antimicrobial activity of Cassia didymobotrya and Phlogacanthus tyrsiflorus. J Chem Pharm Res 2010;2:304-8.

11. Tangjang S, Namsa ND, Aran C, Litin A. An ethnobotanical survey of medicinal plants in the Eastern Himalayan zone of Arunachal Pradesh, India. J Ethnopharmacol 2011;134(1):18-25.

12. Patwari B. A Glossary of Medicinal Plants of Assam and Meghalaya. $1^{\text {st }}$ ed. Guwahati, India: MN Printers; 1992. p. 9.

13. Jaiswal V. Culture and ethnobotany of Jaintia tribal community of Meghalaya, Northeast India: A mini review. Indian J Tradit Knowl 2010;9:38.

14. Chakravarty S, Kalita JC. Antihyperglycaemic effect of flower of Phlogacanthus thyrsiflorus nees on streptozotocin induced diabetic mice. Asian Pac J Trop Biomed 2012;2:S1357-61.

15. Tiwari P, Kumar B, Kaur M, Kaur G, Kaur H. Phytochemical screening and extraction: A review. Int Pharm Sci 2011;1:98-106.

16. Singleton VL, Orthofer R, Lamuela-Raventós RM. Analysis of total phenols and other oxidation substrates and antioxidants by means of Folin-Ciocalteu reagent. Methods Enzymol 1999;299:152-78.

17. Arvouet GA. Standardisation of the extract of plant and identification of the principal constituents. J Pharmocol 1994;49:462-8.

18. Hoelzl C, Bichler J, Ferk F, Simic T, Nersesyan A, Elbling L, et al. Methods for the detection of antioxidants which prevent age related diseases: A critical review with particular emphasis on human intervention studies. J Physiol Pharmacol 2005;56 Suppl 2:49-64.

19. Brand-Williams W, Cuvelier ME, Berset C. Use of free radical method to evaluate antioxidant activity. Lebensm Wisst Technol 1995;28:25-30.

20. Patel A. Determination of polyphenols and free radical scavenging activity of Tephrosia purpurea Linn leaves (Leguminosae). Pharmacogn Res 2010;2:152-8.

21. Marcocci L, Maguire JJ, Droy-Lefaix MT, Packer L. The nitric oxide scavenging property of Ginko biloba extract. Biochem Biophys Res Commun 1994;201:748.

22. Dinis TC, Maderia VM, Almeida LM. Action of phenolic derivatives (Acetaminophen, salicylate, and 5-aminosalicylate) as inhibitors of membrane lipid peroxidation and as peroxyl radical scavengers. Arch Biochem Biophys 1994;315(1):161-9.

23. Prieto P, Pineda M, Aguilar M. Spectrophotometric quantitation of antioxidant capacity through the formation of a phosphomolybdenum complex: Specific application to the determination of vitamin E. Anal Biochem 1999;269(2):337-41.

24. Lee JC, Kim HR, Kim J, Jang YS. Antioxidant property of an ethanol extract of the stem of Opuntia ficus-indica var. saboten. J Agric Food Chem 2002;50(22):6490-6.

25. Larsen PL. Aging and resistance to oxidative damage in Caenorhabditis elegans. Proc Natl Acad Sci U S A 1993;90(19):8905-9.

26. Mahajan-Miklos S, Tan MW, Rahme LG, Ausubel FM. Molecular mechanisms of bacterial virulence elucidated using a Pseudomonas aeruginosa-Caenorhabditis elegans pathogenesis model. Cell 1999;96(1):47-56

27. Goel MK, Khanna P, Kishore J. Understanding survival analysis: Kaplan-Meier estimate. Int J Ayurveda Res 2010;1(4):274-8.

28. Violi F, Marino R, Milite MT, Loffredo L. Nitric oxide and its role in lipid peroxidation. Diabetes Metab Res Rev 1999;15(4):283-8.

29. Halliwell B, Gutteridge JM. The definition and measurement of antioxidants in biological systems. Free Radic Biol Med 1995;1(1)8:125-6.

30. Smith TJ. Squalene: Potential chemopreventive agent. Expert Opin Investig Drugs 2000;9(8):1841-8.

31. Lee KL, Lee SH, Park KY. Anticancer activity of phytol and eicosatrienoic acid identified from Perilla leaves. J Korean Soc Food Sci Nutr 1999;28:1107-12

32. Vivancos M, Moreno JJ. beta-Sitosterol modulates antioxidant enzyme response in RAW 264.7 macrophages. Free Radic Biol Med 2005;39(1):91-7

33. Yoshida Y, Niki E. Antioxidant effects of phytosterol and its components. J Nutr Sci Vitaminol (Tokyo) 2003;49(4):277-80.

34. Hecht SS. Chemoprevention by isothiocyanates. J Cell Biochem Suppl 1995;22:195-209.

35. Hunter T, Bannister WH, Hunter GJ. Cloning, expression, and characterization of two manganese superoxide dismutases from Caenorhabditis elegans. J Biol Chem 1997;272(45):28652-9.

36. Fujii M, Ishii N, Joguchi A, Yasuda K, Ayusawa D. A novel superoxide dismutase gene encoding membrane-bound and extracellular isoforms by alternative splicing in Caenorhabditis elegans. DNA Res 1998;5(1):25-30

37. Honda Y, Honda S. The daf-2 gene network for longevity regulates oxidative stress resistance and Mn-superoxide dismutase gene expression in Caenorhabditis elegans FASEB J 1999; 13:1385-93.

38. Ayyadevara S, Dandapat A, Singh SP, Siegel ER, Shmookler Reis RJ, Zimniak L, et al. Life span and stress resistance of Caenorhabditis elegans are differentially affected by glutathione transferases metabolizing 4-hydroxynon-2-enal. Mech Ageing Dev 2007;128(2):196-205.

39. Gems D, McElwee JJ. Broad spectrum detoxification: The major longevity assurance process regulated by insulin/IGF-1 signaling? Mech Ageing Dev 2005;126(3):381-7.

40. Shmookler Reis RJ, Kang P, Ayyadevara S. Quantitative trait loci define genes and pathways underlying genetic variation in longevity. Exp Gerontol 2006;41(10):1046-54.

41. Cezairliyan B, Vinayavekhin N, Grenfell-Lee D, Yuen GJ, Saghatelian A, Ausubel FM. Identification of Pseudomonas aeruginosa phenazines that kill Caenorhabditis elegans. PLoS Pathog 2013;9(1):e1003101.

42. McFarland AJ, Anoopkumar-Dukie S, Perkins AV, Davey AK, Grant GD. Inhibition of autophagy by 3-methyladenine protects 1321N1 astrocytoma cells against pyocyanin- and 1-hydroxyphenazine-induced toxicity. Arch Toxicol 2012;86(1):275-84

43. Aballay A, Drenkard E, Hilbun LR, Ausubel FM. Caenorhabditis elegans innate immune response triggered by Salmonella enterica requires intact LPS and is mediated by a MAPK signaling pathway. Curr Biol 2003;13(2):47-52

44. Kim DH, Feinbaum R, Alloing G, Emerson FE, Garsin DA, Inoue H, et al. A conserved p38 MAP kinase pathway in Caenorhabditis elegans innate immunity. Science 2002;297(5581):623-6.

45. Rincón M. MAP-kinase signaling pathways in T cells. Curr Opin Immunol 2001;13(3):339-45.

46. Shrestha P, Hnadral M. Evaluation of immunomodulatory activity of extract from the rind of Nephelium lappaceum fruit. Int J Pharm Pharm Sci 2017;9:38-43.

47. Reddy PG, Kothai AR, Thenmozhi M, Dhanalakshmi M, Sarumathy S, Manjuladevi K. Evaluation of immunomodulatory activity of aqueous extract of a polyherbal formulation by in vivo method. Asian J Pharm Clin Res 2013;6:129-33. 